\title{
Cytological Diagnosis of Primary Thyroid Tuberculosis
}

\author{
Prashant Goyal, ' Deepti Mittal,, Soumyesh Ghosh,' Dipti Agrawal,, ${ }^{2}$ Shelly Sehgal,' Sompal Singh \\ 'Department of Pathology, Swami Dayanand Hospital, Delhi, 1 10095, India, ${ }^{2}$ Department of Gynaecology, Swami \\ Dayanand Hospital, Delhi-1 10095, India.
}

\section{ABSTRACT}

Primary thyroid tuberculosis is an extremely rare disease, even in countries where other forms of tuberculosis are abundant. TT has no age bar but usually affects women in fourth and fifth decade. Hereby, we report a case of 16-years-old girl presented with complaint of progressively increasing, painful thyroid swelling. Diagnosis of TT was made on cytology and there was no evidence of involvement of any other organ by tuberculosis. Despite of its rarity, TT is usually misdiagnosed. So, a clinician should always consider this entity in the differential diagnosis of thyroid swelling. Fine needle aspiration cytology is the best diagnostic method and can result in the avoidance of unnecessary thyroid surgeries.

Keywords: cytology; granuloma; thyroid; tuberculosis.

\section{INTRODUCTION}

Tuberculosis of thyroid gland (TT), rather primary or secondary, is an extremely rare disease, even in countries where tuberculosis in an endemic disease. ${ }^{1}$ Because of its rarity, it is generally not considered as differential diagnosis in case of thyroid swellings. Hereby, we report a case of 16-years old female presenting with primary TT which was diagnosed on cytology.

\section{CASE REPORT}

A 16-year-old girl presented with complaint of progressively increasing, slightly painful swelling in midline of neck since one month. There was no history of fever, cough, hemoptysis, dyspnea, dysphagia and weight loss. No symptoms of thyroid dysfunction were present. There was no significant family and past medical history. Local examination revealed an oval shaped, $5 \times 2.5 \mathrm{~cm}$ sized, firm thyroid swelling which was more on left side (Figure 1). The swelling was moving on deglutition. Overlying skin was inflamed. No palpable cervical lymph nodes were noted. Physical examination including respiratory system revealed no abnormality.

Correspondence: Dr. Dipti Agrawal, Department of Gynaecology, Swami Dayanand Hospital, Delhi, 110095 , India. Email: drdipti.goyal@yahoo.in, Phone: +91-9718651169. 


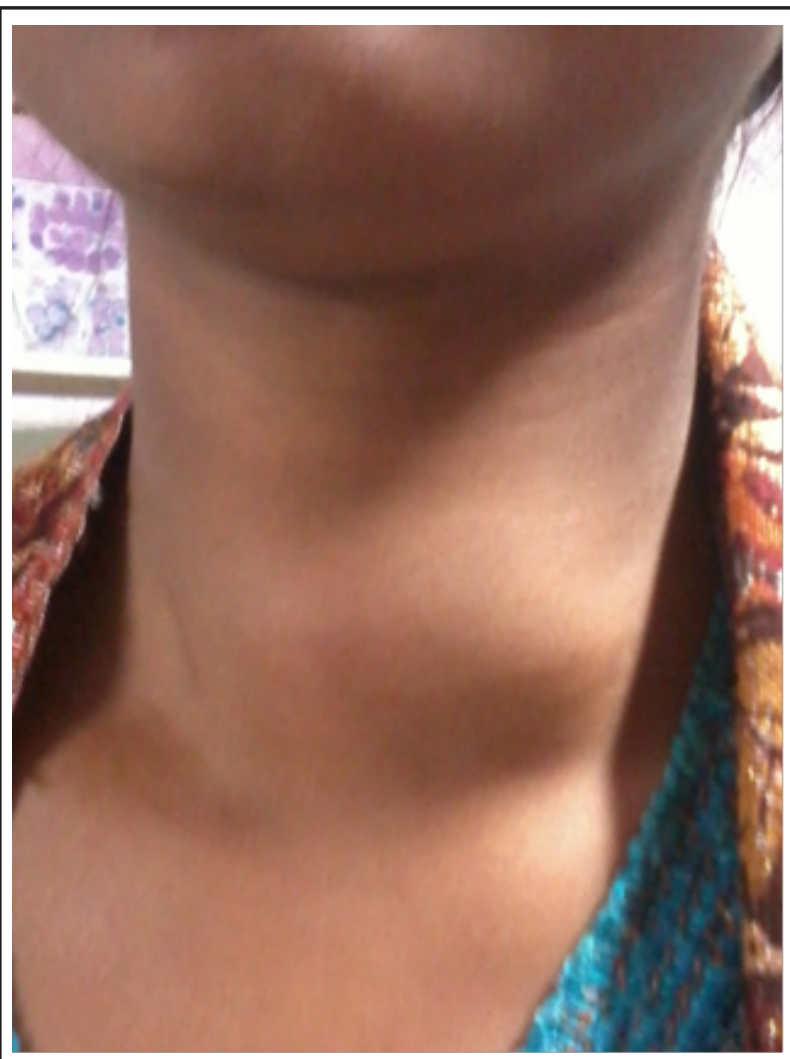

Figure 1. Asymmetrical thyroid swelling in a 16-yearold female.

Routine blood count, biochemistry and urine analysis were within normal limits. Erythrocytic sedimentation rate (ESR) was $38 \mathrm{~mm}$ after one hour by westergren method. Mantoux test resulted in $22 \mathrm{~mm}$ induration at 48 hours. The patient was seronegative for HIV. Thyroid function tests were within limits (Free T3= $2.9 \mathrm{pg} / \mathrm{ml}$; Free $\mathrm{T} 4=1.0 \mathrm{ng} / \mathrm{dL}$ and $\mathrm{TSH}=3.9 \mu \mathrm{lU} /$ $\mathrm{ml}$ ). Chest x-ray and abdominal ultrasound were unremarkable. The patient was advised for fine needle aspiration cytology (FNAC). FNA was performed with a 23 gauge needle and suction applied by $10 \mathrm{ml}$ syringe. Scanty blood mixed pus was obtained and smeared on glass slides. Smears were stained with May-GrunwaldGiemsa (MGG) stain and Ziehl-Nelsen stain (ZN stain). Cytosmears showed casseous necrosis, epithelioid cell granulomas, and occasional giant cells in the background of inflammatory exudates (Figure 2). However, ZN stain for acid fast bacilli (AFB) was negative. On the basis of above findings, diagnosis of primary TT was made. Incision and drainage was performed and the patient was started on antitubercular therapy. Though there was significant clinical improvement, the patient discontinued the treatment after 3 months and became defaulter. After ten months, she again presented to us with a left supraclavicular lymph node enlargement and normal thyroid gland. FNAC from left supraclavicular lymph node showed features of tubercular lymphadenitis. The patient was counseled and antitubercular therapy was reinstituted.

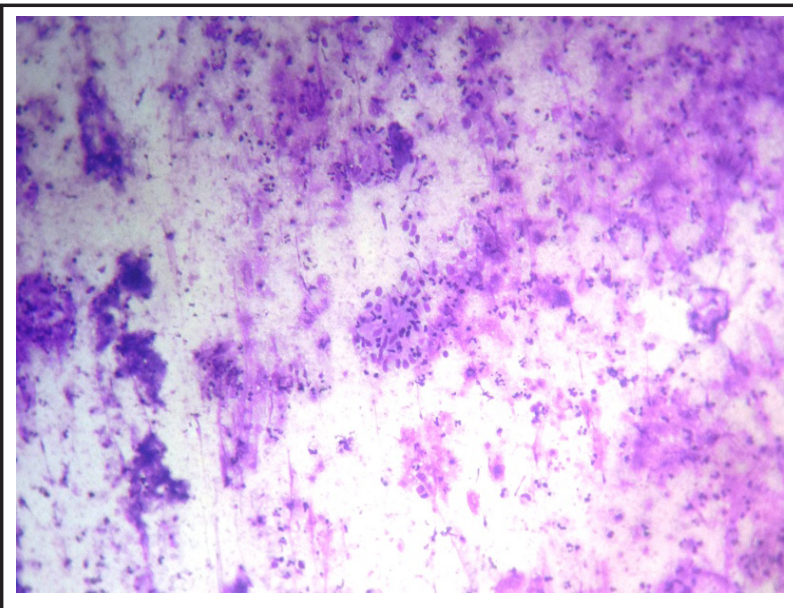

Figure 2. Cytosmear showing epithelioid cell granulomas in the background of acute inflammatory exudates (MGG stain, $\times 100$.

\section{DISCUSSION}

Even in countries, like India, where tuberculosis is an endemic disease, thyroid tuberculosis is incidentally diagnosed. ${ }^{1}$ According to previous studies in literature, incidence of tuberculosis in thyroid gland was less than $1.1 \% .^{2-4}$ In last three years, we performed 463 FNACs from thyroid lesions, out of which this was the only maiden case of TT.

TT can be primary or secondary but primary disease is much rarer and more difficult to diagnose. ${ }^{5}$ Resistance of thyroid gland to tuberculosis may be due to its high vascularity, rich lymphatics, strong capsule and bactericidal effect of colloid and iodine..$^{6-8}$

TT usually affects middle aged women (age range 30 to 46 years) $)^{2,3}$ but in our case, the patient was a 16 year old girl. Patients with thyroid tuberculosis are usually asymptomatic and sometimes, present with solitary thyroid nodule or diffuse thyroid enlargement. So, may be clinically misdiagnosed as colloid goiter, grave's disease, various types of thyroiditis and even thyroid neoplasm. ${ }^{9}$ Few cases of coexistence of malignancy and tuberculosis in thyroid have been also reported in literature. ${ }^{10}$ Patients with TT can also present with abscess formation due to secondary infection as in our case. Most of the patients are euthyroid as in our case but both hypothyroidism due to gland destruction and hyperthyroidism due to increased secretion of thyroid hormone also not uncommon. ${ }^{8}$ That's why, thyroid function tests do not aid in diagnosis of TT. ${ }^{5}$ Ultrasound of neck usually shows heterogenous, hypoechogenic mass, however, not helpful in establishing the diagnosis. ${ }^{5}$ 
Goyal et al. Cytological Diagnosis of Primary Thyroid Tuberculosis

FNAC is the main modality to diagnose and differentiate TT from other thyroid pathologies and thus, helps to prevent unnecessary thyroid surgeries. FNAC findings include epithelioid cell granuloma, casseous necrosis and Langhen's giant cells. Although, epithelioid cell granuloma is not specific, presence of casseous necrosis confirms the diagnosis of tuberculosis. The presence of AFB in the aspirated material by $\mathrm{ZN}$ stain can also validate the diagnosis; however, tubercular bacilli are rarely identified by the stain. High ESR and a positive Mantoux test may also be contributory while making the diagnosis. Other investigations like chest X-ray, sputum examination and abdominal ultrasound can also help in searching other sites involved by tuberculosis.

The main treatment modality is medical, based on anti-tubercular drugs. If patient presents with abscess formation, then incision and drainage combined with anti-tubercular therapy is considered. Further surgical intervention is usually not required. ${ }^{8}$

Primary TT is an extremely rare disease even in endemic areas but clinician should always consider this entity in the differential diagnosis of any thyroid swelling. FNAC is the main diagnostic modality and can help in avoiding unnecessary thyroid surgeries.

\section{REFERENCES}

1. Dawka S, Jayakumar J, Ghosh A. Primary tuberculosis of the thyroid gland. Kathmandu Univ Med J (KUMJ). 2007 Jul-Sep;5(3):405-7.

2. Mondal A, Patra DK. Efficacy of fine needle as piration cytology in the diagnosis of tuberculosis of the thyroid gland: a study of 18 cases. J Laryngol Otol. 1995;109:36-8.

3. Das DK, Pant CS, Chachra KL, Gupta AK. Fine needle aspiration cytology diagnosis of tuberculous thyroiditis. A report of eight cases. Acta Cytol. 1992;36: 517-22.

4. Šimkus A. Thyroid tuberculosis. Medicina. 2004;40:201-4.

5. Endah I, Daghfous H, Ben Mrad S, Tritar F. Primary tuberculosis of the thyroid gland. Hormones (Athens). 2008 Oct-Dec;7(4):330-3.
6. Bulbuloglu E, Ciralik H, Okur E, Ozdemir G, Ezberci F, Cetinkaya A . Tuberculosis of he Thyroid Gland: Review of the Literature. World J Surg. 2006;30:149-55.

7. Sahoo M, Kaushik S, Bhatnagar A, Kashyap R. Role of Fine Needle Aspiration Cytology, Ultrasound and Tc99m Scan in the Diagnosis of Thyroid Tuberculosis. IJNM. 2005;20:83-7.

8. Das SK, Bairagya TD, Bhattacharya S, Barman DC. Tuberculosis of the thyroid gland. Indian J Lepr. 2012 Apr-Jun;84(2):151-4.

9. Razmpa E, Sharifian H, Sadeghi-Hasanabadi M, Ilami A Shahinfar SH. Clinical and paraclinical aspects of thyroid tuberculosis. Acta Med Iran. 2007;45:389-94.

10. Meng L, Hu S, Huang L, Xu C. Papillary thyroid cancer coexisting with thyroid tuberculosis: A case report. Oncol Lett. 2014 May;7(5):1563-1565. 